\title{
Are Cities Developing Climate Change Awareness? Two Case Studies for Assessing and Developing Cities' Climate Awareness Through a Framework
}

\section{Marta Iturriza}

University of Navarra: Universidad de Navarra

Josune Hernantes

University of Navarra: Universidad de Navarra

Leire Labaka ( $\square$ llabaka@tecnun.es )

University of Navarra: Universidad de Navarra https://orcid.org/0000-0002-1721-0624

\section{Research Article}

Keywords: climate change, climate awareness, framework

Posted Date: March 11th, 2021

DOI: https://doi.org/10.21203/rs.3.rs-274363/v1

License: (c) (i) This work is licensed under a Creative Commons Attribution 4.0 International License.

Read Full License 


\section{Abstract}

Cities are dealing with the challenge of climate change (CC). However, due to a lack of awareness on the part of certain city stakeholders, cities' plans, strategies and studies dealing with CC have been hampered. Studies have demonstrated that city stakeholders become engaged and act collaboratively when they become aware of $\mathrm{CC}$, yet the studies that highlight the need to become aware do not address how this awareness might be developed. This paper presents a framework to develop climate awareness in city stakeholders through a co-creation process that uses different research methods and 67 expert participation of different nationalities and backgrounds. The framework, under the name Climate Awareness Development framework, defines the city stakeholder climate awareness-development process through four attributes that are activated by four mechanisms during a four-step gradual process that leads to higher awareness levels. The steps are complemented by a set of nine policies that boost progression along the four-step process. The contribution of our research is highlighted through the comparison of two case studies in the city of Kristiansand (Norway) and Donostia (Spain).

\section{Introduction}

Humans have been adapting to the challenges posed by their surroundings throughout history. However, the challenges presented by climate change (CC) differ from other environmental challenges owing to their uncertainty in both short- and long-term climatic scenarios as well as the magnitude at which they affect sectors like the economy or health both globally and locally (Moglia et al. 2018). CC is a global challenge that will change the world if greenhouse gas emissions are not drastically reduced by more than half (IPCC 2018).

Urban areas are where many of the critical challenges derived from CC will play out. In fact, as centres of population and economic activity, cities will become more vulnerable to the dynamism and uncertainty that arise from CC as they continue to expand (Al-Awadhi et al. 2019). Cities recognise their role as contributors to $\mathrm{CC}$ and they are attempting to reduce their impact on the environment while simultaneously building resilience to the irreversible effects of CC and transforming themselves into more sustainable cities (Moglia et al. 2018). However, cities are used to tackling these challenges through traditional crisis management, but due to the $\mathrm{CC}$ characteristics mentioned above, dealing with the challenges posed by $\mathrm{CC}$ requires that they shift to a climate-resilience approach and become sustainable cities by adopting transformative thinking and action.

In this context, several studies and strategies that aim to shift cities to the climate-resilience approach and transform into a sustainable city have been developed: the Covenant of Mayors, 100 Resilient Cities, the Sendai Framework for Disaster Risk Reduction and the Habitat III New Urban Agenda. However, different studies in the literature have highlighted that the effectivity of city resilience-building strategies depends on different factors such as a city's system of governance, society and economy, and its natural resources and infrastructures (Simonet and Leseur 2019). Not considering all these factors while building city resilience means the developed strategies will be less effective than planned and hamper a city's 
transformation into sustainable urban system (Torabi et al. 2018). In this research, we focus on city governance, and more precisely, on the role and behaviour of certain city stakeholders and their impact on the development of resilience. In practice, the lack of proactive behaviour on the part of certain city stakeholders' during the process of operationalizing city resilience has resulted in wasted effort or maladaptation (Keenan 2018).

In this study, city stakeholders are divided into three groups (Gimenez et al. 2017): public entities (local governments, governmental associations), private companies (companies, academia or professional associations) and community groups (civil society organizations, donors).

Ensuring stakeholders' proactivity is crucial in order to effectively operationalize city resilience (Keenan 2018). In this vein, it has been demonstrated that the developing city stakeholders' awareness before and during the building of city resilience in the $\mathrm{CC}$ context is an effective way to transform behaviour from being passive to proactive (Burnside-Lawry and Carvalho 2016; Luís et al. 2018; Poponi et al. 2019). Awareness influences stakeholders' perception and attitude about climate change and, as a result, encourages that action and policies that reduce the effect of CC be undertaken (UNISDR 2009). However, despite the recognition that stakeholders need to develop climate awareness, there is a lack of clear guidance as to how awareness should be developed, what policies are needed to boost awareness, and who should lead the policies that develop awareness (Burnside-Lawry and Carvalho 2016). In light of this, this paper seeks to present the Climate Awareness Development framework that proposes a process for guiding city stakeholders' climate awareness development.

The paper starts with the state of the art concerning awareness and the existing frameworks for developing awareness (Sect. 2). Then, our research methodology is described (Sect. 3), followed by the explanation of the framework (Sect. 4). Next, the comparison of the conducted case studies is described (Sect. 5). Finally, the paper ends with a discussion and wraps up with the main conclusions in Sect. 6.

\section{State Of The Art}

Climate awareness has been characterized in different ways in the literature, and different studies have focused on different attributes to define awareness. UNISDR (2009) has defined climate awareness as "the process of informing the general population, increasing levels of consciousness about risks and how people can act to reduce their exposure to hazards".

Overall, the studies in the literature characterize climate awareness as the perception of CC as a relevant problem for the sustainability of our planet and consequently for our wellbeing. Literature concludes that if we do not have a CC-related experience and start perceiving CC as a problem, we are not going to take action towards mitigating and adapting to it (UNISDR 2009; Neo et al. 2017; Prescott et al. 2019). Hence, experiencing and consequently having knowledge of the risks and the impacts caused by CC is a key factor in understanding how the problem of $\mathrm{CC}$ is essential to our wellbeing and how critical it is that we deal with it (UNISDR 2009; Lieske et al. 2014; Larson et al. 2017; Neo et al. 2017; González-Hernández et al. 2019; Prescott et al. 2019). A second definition of climate awareness makes reference to the level of 
attention we pay to $\mathrm{CC}$, where attention is understood as the willingness to act and participate in implementing the measures required to face the challenges posed by $\mathrm{CC}$ in an active and committed way (UNISDR 2009; Liu et al. 2010; Lieske et al. 2014; Nguyen et al. 2015; Sima 2016; Larson et al. 2017; Neo et al. 2017; Yin et al. 2018; Berndtsson 2019; González-Hernández et al. 2019; Prescott et al. 2019).

Finally, when defining climate awareness literature also poses that acting collaboratively helps to improve and maintain the level of awareness over time since collaboratively facing the problem enriches communication among the stakeholders, which in turn leads to a higher level of experience, knowledge and attention in facing CC (Sima 2016; Yin et al. 2018; Prescott et al. 2019).

Based on our analysis of the above studies, we have concluded that the frameworks that aim to build city resilience characterize awareness based on the following attributes: experience, knowledge, attention and collaboration (see Table 1).

Table 1

Attributes that define awareness in the context of CC

\begin{tabular}{|c|c|c|c|c|}
\hline AUTHOR (Year) & ATTRIBUTES & & & \\
\hline & EXPERIENCE & KNOWLEDGE & ATTENTION & COLLABORATION \\
\hline UNISDR (2009) & $x$ & $x$ & $x$ & \\
\hline Liu et al. (2010) & & & $x$ & \\
\hline Lieske et al. (2014) & & $x$ & $x$ & \\
\hline Nguyen et al. (2015) & & & $\mathrm{x}$ & \\
\hline Sima et al. (2016) & & & $\mathrm{x}$ & $x$ \\
\hline Larson et al. (2017) & & $\mathrm{x}$ & $\mathrm{x}$ & \\
\hline Neo et al. (2017) & $\mathrm{X}$ & $\mathrm{x}$ & $\mathrm{x}$ & \\
\hline Yin et al. (2018) & & & $\mathrm{x}$ & $X$ \\
\hline Berndtsson et al. (2019) & & & $\mathrm{x}$ & \\
\hline $\begin{array}{l}\text { González-Hernández et al. } \\
\text { (2019) }\end{array}$ & & $X$ & $X$ & \\
\hline Prescott et al. (2019) & $x$ & $x$ & $x$ & $x$ \\
\hline
\end{tabular}

Recent studies have highlighted the positive effects of increasing awareness: it enhances stakeholder proactivity, improves city resilience operationalization and it transforms cities into sustainable cities (Liu et al. 2010; Al-awadhi et al. 2019; Olazabal et al. 2019). For example, Olazabal et al. (2019) evaluated four cities' climate resilience based on those cities' frameworks and highlighted the weaknesses and strengths of each case. One of their main conclusions was that the four cities needed to develop stakeholders' climate awareness to improve their city resilience level. 
However, despite the recognition of the need to develop stakeholders' climate awareness in order to improve the implementation of climate-resilient strategies, there is a lack of clear definition with regard to what the process to develop climate awareness should be (Burnside-Lawry and Carvalho 2016; Keenan 2018; Simonet and Leseur 2019).

In this vein, several studies have studied the mechanisms that define cities' behaviour toward the environment (Gifford et al., 2011). Rogers (1975) used the "protection motivation" theory to explain the process that cities followed to respond to triggering events such as floods. The framework he proposed suggested that any adaptation process was initiated by stressors that derived a behavioural response. Following Rogers (1975), Xie et al. (2019) studied cities' climate perception and their consequent behaviour through an online questionnaire given to 921 Australian citizens. The authors concluded that the process cities followed to face $\mathrm{CC}$ was driven by lived $\mathrm{CC}$ experiences and the attention given to the topic.

Similarly, recent studies have focused on assessing cities' climate awareness to understand the lack of awareness of certain city stakeholders (Lieske et al. 2014; Toubin et al. 2014; Guo and Tang 2017; Saxena et al., 2018; Xie et al., 2019). For example, Saxena (2018) carried out 35 interviews on a small Caribbean island to analyse stakeholders' knowledge of and practices towards CC. They concluded that one of the reasons stakeholders adopted passive behaviour was the lack of sufficient data to inform climate-resilience work. These studies concluded that cities' current CC awareness level depends not only on their size but also on stakeholder characteristics in terms of education and culture, political affiliation, gender, age average and past experience with extreme CC events (Saxena 2018). However, the studies do not specify how awareness should be developed.

Other researchers have analysed the process for developing climate awareness for only one of the city stakeholder type, usually community groups. For example, Drummond et al. (2018) studied community groups' awareness in 71 countries and analysed the strong influence that the design of CC mitigation policies has on community groups when developing climate awareness. Siriporananon and Visuthismajarn (2018) conducted a study in Hat Yai, Thailand, to study the success of the policies defined by the Asian Cities Climate Change Resilience Network. The study concluded that even though policies target city stakeholders' awareness development can be found, the policies are not as effective as expected, because they were focused only on running workshops and sharing knowledge among city stakeholders.

The above-mentioned studies address very specific issues and are only oriented toward community groups, rather than considering public entities and private companies as well in a bid to deal with CC in a transversal way. Furthermore, while they analyse the mechanisms that influence awareness development, they do not define an ideal process that will make cities aware of CC. For this last issue, there are studies that define awareness-development processes for sustainable habits such as energy consumption and resilient building for tsunami response (Tàbara et al., 2010; Henly-Shepard et al. 2015; Shrouf et al. 2017). Shrouf et al. (2017) conducted a pilot study to provide a way to achieve stakeholders' awareness of 
energy usage during production processes. The study concluded with seven gradual steps that ranged from assessing current awareness to designing a set of indicators and defining specific actions to develop awareness and increase energy consumption effectiveness. Taking a different approach, HenlyShepard et al. (2015) defined a three-phase social learning framework for transforming cities' resilience capacities to the specific case of tsunamis. The study explained how the study participants transformed their thoughts from thinking individually to thinking collectively. On a broader level, Tàbara et al. (2010) used Arnstein's (1969) concept of a learning ladder to define a four-step gradual process to develop cities' capacities to adapt to CC, and awareness is presented as one of capacities in the process.

Thus, although several studies present transformation processes that cities have used, none of the studies responds to the specific gap of how to become a climate aware city by engaging all city stakeholders. Our research takes a step further and proposes a framework that defines a climate awareness-development process based on the climate awareness development attributes and mechanisms as well as a set of policies that boost the process (see Sect. 4).

\section{Methods}

The methodology used in our research is structured in three phases: conceptualization, development and validation (Fig. 1). During the overall process, a triangulation approach was taken in order to combine different methodologies (Jick 1979), namely the systematic literature review, semi-structured interviews, the focus group, the Delphi study and the case study to ensure the framework incorporates not only the theory found in the literature but also the expertise of stakeholders and the evidence from the conducted case studies.

\subsection{Conceptualization phase}

A systematic literature review was conducted to define the context and contribution of our research. The review was oriented to search for studies concerning both the relationship between awareness and resilience and awareness development over time. The three main keywords used were "awareness" AND "climate change" AND "city resilience", and they were complemented with other keywords to obtain more specific publications. As a result, of the initial 92 papers found, a total of 48 were selected. Further detail about the literature review is in Iturriza et al. (2020).

The 48 papers that emerged from the systematic literature review were used to define the framework's four preliminary awareness attributes and awareness mechanisms and the four-step awarenessdevelopment process.

\subsection{Development phase}

The development phase used a co-creation process with experts. In total, 67 experts from different nationalities and backgrounds participated, ensuring equilibrium. The experts represented public entities (36\%), private companies (35\%) and community groups (29\%). The experts who collaborated in the study 
did not participate in more than one method, except for some experts that participated in the initial semistructured interviews and in the focus group.

The development phase of the methodology started with ten semi-structured interviews. The interviews consisted of an introductory video and five mandatory questions concerning the four awareness attributes, the four mechanisms and the awareness-development process. During the interviews, the experts answered the mandatory questions and had the chance to make suggestions and comments. As a result, the preliminary awareness attributes and mechanisms (Sect. 4.1 and Sect. 4.2), as well as the four-step awareness-development process defined in the literature review (Sect. 4.4), were updated. Moreover, the experts suggested defining the participation of each stakeholder and identifying policies to bolster the awareness-development process (Sect. 4.3).

The subsequent focus group and Delphi study aimed to define a set of policies, the effect of these policies on the framework and the city stakeholder that should lead each policy. Focus groups are designed to collect data from participants through the group's interaction on a topic chosen by the researcher (Morgan 1997), and in this vein we ran three different activities with the ten experts participants: (1) framework familiarization, (2) definition of a preliminary set of policies, (3) definition of the final set of policies and the stakeholders in charge. As a result of these activities, a list of nine policies and the city stakeholder that should implement each was obtained. Following the focus group, the Delphi study was carried out with 29 experts, who were asked more specific questions to validate the results of the focus group and further study the policies. The Delphi method is a systematic and iterative survey process for structuring a group communication process in order to obtain consensus about a complex problem under study (Dalkey 1969). The Delphi process that was conducted consisted of two rounds of questionnaires. The first-round questions focused on gathering information about policy definition, policy relevance and stakeholder in charge, while the second-round questionnaire focused on the policy implementation order. By the end of the Delphi study, the nine preliminary policies defined in the focus group had been validated, the role of each city stakeholder had been defined, and the most effective order for implementing the policies had been specified. The policies are presented in Sect. 4.3.

\subsection{Validation phase}

Two case studies were conducted to confirm that the framework contributes in a complete and relevant way to the lack of climate awareness development processes at a city scale. Case studies explore and study real-life events and their relationships in a detailed analysis. The two case studies took place in the city of Kristiansand (Norway) and Donostia (Spain).

Kristiansand is the administrative, business and cultural centre of Southern Norway, with a total of 97,846 inhabitants living in its urban area. This coastal city is known for its extensive processing industry and a great amount of economic activity at its harbour. Being a coastal city, Kristiansand is dealing with the direct effects of $\mathrm{CC}$, as the global warming that causes the sea level rise and wild-extreme tides are flooding the city and creating severe damage, hampering the proper operation of the industry situated at the harbour. In 2017, Kristiansand suffered extreme floods that caused significant damage to the urban 
area. As a consequence of this and similar events derived from CC, Kristiansand has made an effort to create public-private collaborations and develop its resilience through plans to equip its community, industries, environment and organizations.

Donostia is a coastal city located in the north of Spain, with a total of 186,000 inhabitants. In recent years, the city has experienced unusual heatwaves and heavy rains that have caused unexpected floods and high, violent sea tides that have flooded the streets with seawater and damaged them. Consequently, the city has been working on its CC strategy and proactively taken part in European projects to build climate awareness as well as city resilience.

Given these two cities' current work in building climate awareness, they were suitable choices for our case studies because we assumed that their stakeholders have a great deal of embedded knowledge to contribute validate the framework.

A total of 22 experts took part in the case studies: 11 in Kristiansand and 11 in Donostia. Semi-structured interviews were conducted to ask about the policies defined in our framework and to know the implementation level of the policies in both cities. The participants were also asked about what barriers in their daily activities keep them from developing climate awareness and building city resilience. The data gathered in the interviews were triangulated with online reports and publications. Finally, outcomes were shared with the participants. As a result, the validation phase concluded with the relevance, completeness and usefulness of the framework (see Sect. 5).

\section{Framework For Developing City Stakeholders' Climate Awareness}

The Climate Awareness Development framework provides city stakeholders with a process to develop climate awareness. The framework defines four sequential steps that stakeholders need to go through when developing climate awareness. The framework starts with the lower level of awareness, "Step 1: Passive", and ends with the highest level, "Step 4: Synergies". Each step describes a generic characterization of the process for developing climate awareness at a city scale based on the elements of the framework: 1) the attributes that define climate awareness, 2) the climate awareness development mechanisms, 3) the policies for developing climate awareness and 4) the progressive four-step process (see Fig. 2). Further explanation of how the process has been defined is in Iturriza et al. (2020).

Table 2 illustrates the complete framework, which includes the four steps, a short description of the step's objectives, the attributes that define awareness, the mechanisms that explain the awareness process, and a set of policies to be implemented to move from one step to the next. The mechanisms, the four steps and the policies are explained in detail below.

\subsection{Awareness attributes}

The literature review identified the main attributes used to define climate awareness in the context of building city resilience (see Sect. 2). Based on the four attributes (experience, knowledge, attention and 
collaboration) identified in this research we define climate awareness as having experienced and knowing about CC as a hazard as well as increasing attention to CC by having the willingness to take action and participate in a collaborative way to adapt to and face the challenges of CC.

The attribute experience refers to the lived real-life practices related to a specific problem (Anguelovski et al. 2014). Having a high degree of experience means having gained experience by being involved in that problem. In this sense, experience can be lived first- or second-hand. In the case of CC, having first-hand experience means having gained experience by living through a consequence of $\mathrm{CC}$, whereas secondhand experience would be to gain experience by hearing someone's lived experience of a CC-related event.

The attribute knowledge refers to the quantity and quality of information about a problem. In order to acquire knowledge and be considered as having a high level of knowledge about a topic, the available information needs to be collected and analysed. Developing climate awareness is largely dependent on the availability and quality of information concerning CC (Street et al. 2016).

Moreover, the attribute attention refers to being alert and having the willingness to act upon a problem in a committed way (Sollberger et al. 2017). Of the four attributes, this is the one that concerns behaviour. Having a high attention level implies that attention has been generated by being alert to what is happening in the immediate environment and committing to action. Several studies have shown that attention might differ depending on gender, age, political affiliation and past experiences (Paterson and Charles 2019).

Finally, the attribute collaboration refers to working across boundaries and in multi-stakeholder relationships (Oxley 2013). Hence, creating collaboration entails conducting a set of activities directed towards the achievement of common goals to initiate new collaboration networks. Maintaining climate awareness requires the collaboration and coordination of all stakeholders. Strategic alliances predicated on collaboration are what allow inter-agency dialogue to take place, resources to be pooled and duplication of efforts to be avoided (Evers et al. 2016).

\subsection{Awareness-development mechanisms}

Our next step is to define a detailed process that covers how to develop climate awareness when building city resilience efficiently and effectively. To that end, and following the literature, in this section we identify the mechanisms that determine how the attributes of climate awareness are activated during the resilience-building process. The identified mechanisms, which are closely related to the attributes, are: gaining experience, acquiring knowledge, generating attention and creating collaboration.

The names of the mechanisms seem to imply a direct relationship between the four attributes and the mechanisms, yet the mechanisms are interrelated to each other and are activated in different points of the climate awareness development process. The predominance of any given mechanism will vary during the awareness-development process. Figure 3 summarizes the dynamic relationships between the mechanisms and the attributes during the process through a causal loop diagram. The mechanisms are shown as loops, and the attributes are related by arrows. Figure 3 represents how this process is initiated: 
first, loop B1 is activated, and in turn R1 will be activated, followed by R2, and finally R3. Thus, to initiate the process, stakeholders must first experience a CC event (Rogers 1975). Experiencing an impact (the B1 loop) brings about a clear change in the city stakeholders' climate awareness since they clearly see how badly they could be affected if nothing is done (Sheppard et al. 2011). In this sense, to initiate the climate awareness development process it is key that the impacts experienced be related to CC and not another hazard. As a consequence of the experience gained, stakeholders start to acquire more knowledge about the issue of $\mathrm{CC}$ and have more interest in learning about and understanding this challenge and how to deal with it (R1 loop). Also, attention towards CC is generated (R2 loop) and stakeholders start being more committed and take action to reduce $\mathrm{CC}$ impact and become a more sustainable city. In this context, it is important to ensure that the collaboration and thus the synergies among stakeholders are created (R3 loop), so that awareness reaches its maximum level and is maintained over time by sharing the experience, knowledge and attention developed among stakeholders.

\subsection{Awareness policies}

The development phase of the study resulted in a list of nine policies that should be implemented to develop climate awareness. The list of nine policies was defined at a strategic and aggregated level, and each policy specifies a particular stakeholder in charge of its implementation. Additionally, having the policies defined at an aggregated level increases the generalizability of the policies because stakeholders can particularize the policies to fit their characteristics and urban contexts. In this vein, and based on the literature, a set of sub-policies was defined for each policy to facilitate the characterization of the policies.

The policies shown in Table 2 and defined in Table 3 are the result of the co-creation process and determine what should be done to go from one step to the next in the awareness-development process. Table 2 shows some policies in more than one step because the experts concluded that some policies should be implemented and maintained over time to boost the awareness-development process.

Policy names have been given an acronym to specify the stakeholder type in charge of implementing them (PU: Public entities; PR: Private companies; CG: Community groups). For example, in the first step of the awareness-development process, the policy "CG3: demand a change" is led by community groups and increases attention of CC.

\subsection{Awareness-development process steps}

The Climate Awareness Development framework provides a process that helps city stakeholders to improve their climate awareness and better build city resilience. The process defined in the framework consists of four consecutive. Although not every city will be at the first step, the process aims to both assess and guide stakeholders in achieving the highest climate awareness level.

Each step encapsulates the elements of the framework by determining in a sequential and gradual way the climate awareness mechanisms that are activated, the climate awareness attributes that are achieved and the policies that need to be implemented to advance from one step to the next. Table 2 shows the 
steps, the dominant mechanisms in each step, the attributes achieved and the policies required to advance from one step to the next.

\section{Step 1: Passive}

In this first step, the city stakeholders still doubt the existence of the challenge of CC and have passive behaviour. In order to advance in the awareness-development process, the first requirement is to realize that there is a need (Rogers 1975). The question to answer is, "do we perceive the challenge of CC?" Experience regarding $\mathrm{CC}$ hazards are key in this aspect, since having experienced a CC event makes stakeholders realise what has been done is not enough to face $\mathrm{CC}$, and they start perceiving the existence of the problem and the need to act (Sheppard et al. 2011). Therefore, in this first step, experience is the dominant mechanism. Indeed, suffering CC-related impacts is translated into a higher experience level, which increases awareness and as consequence resilience.

\section{Step 2: Active}

In the second step, awareness has started to develop. Stakeholders perceive and start to understand the vulnerabilities and hazards related to $\mathrm{CC}$, yet they do not act accordingly. As a result, incentives that foster acquiring knowledge should be designed (Poponi et al. 2019). However, one of the three types of city stakeholder needs to lead the behaviour transformation process and incentives. The question in this second step would be, "do we want to make a change?" In this vein, the experience gained from the CCrelated impact leads stakeholders to increase their interest in the topic, and therefore stakeholders start analysing the causes of the problem and obtain more information about the challenge of CC. Thus, stakeholders acquire knowledge of CC. Note that in this second step both awareness and resilience start increasing more rapidly because not only experience but also knowledge is developed.

\section{Step 3: Proactive}

In the third step, experience and knowledge lead to a higher attention level. Consequently, stakeholders behave proactively with regard to CC, but only at an individual level. Each stakeholder acts separately and does not consider possible synergies. As Ban Ki-Moon stated in 2009, leaders should be the example. Yet these leaders can be of any kind (public, private or communities), and the only must is to ensure having committed leaders, as commitment will make them lead and act in a proactive way (Poponi et al. 2019). The question in this step would be, "what can we do to improve this situation?" The stakeholders recognise the vulnerabilities and hazards around them and act accordingly. Even if incentives are applied, in this step actions are carried out altruistically because each stakeholder perceives personal benefits and good in doing so (Tàbara et al. 2009; Siriporananon and Visuthismajarn 2018). Consequently, stakeholders turn out to be a source of feedback and energy. Communication increases among stakeholders and leaders are obliged to continue acting and dealing with the problem of CC (Moser 2016).

\section{Step 4: Synergies}


In the fourth and last step, the experience, knowledge and attention attained lead to collaboration networks such that proactive behaviour towards CC emerges in a multilevel way. Stakeholders not only perceive and understand what is around them, but they are also alert to acting in a committed and collective way to mitigate long-term effects. Stakeholders seek personal convenience as well as universal good that might not directly result in personal benefit. The behaviour in this last step means being in a process of constant change and improvement as existing barriers disappear, silo-thinking is eliminated and stakeholders start to face problems in a collaborative way (Pescaroli 2018). The question in this fourth step would be, "who else can be part of the group?" In this sense, creating collaboration is the dominant mechanism in this last step. This step is key in order to maintain the awareness gained and the resulting resilience level because stakeholders are committed and acting jointly (Toubin et al. 2014). The newly created collaboration networks facilitate communication not only inside the city but also among other cities, and this, in turn, makes it easier to introduce plans and make them more effective. 
Table 3

Policy definitions

\section{POLICY REFERENCE DEFINITION}

$\begin{array}{lll}\text { PUBLIC } & \text { PU1: } & \text { (Poponi et al. } \\ \text { ENTITIES } & \text { DEVELOPMENT } & \text { 2019) } \\ & \text { OF NORMS AND } & \\ & \text { SUSTAINABLE } & \\ & \text { PROCUREMENTS }\end{array}$

PU2: PROVIDE

TOOLKIT TO

DEVELOP PLANS

AGAINST CC

(Keenan 2018)

This policy determines the adoption of existing norms, standards and sustainable procurements but also the development of new norms and sustainable procurements in order to develop awareness and increase city resilience toward CC.

This policy involves developing tools such as an online best practice repository or a handbook of strategic procedures to facilitate the process of building and implementing a resilience plan to face CC.

PU3:

SENSITIZATION ACTIONS
(Luís et al.

2018)
This policy consists of carrying out sensitization actions such as incentives to recycle, studies about CC, workshops concerning sustainability habits or creative participatory sessions with any of the three city stakeholder types.
PRIVATE COMPANIES
PR1:

CORPORATE RESPONSIBILITY ACTIONS
(Siriporananon and Visuthismajarn 2018)

This policy consists of carrying out transparency actions such as publishing companies' emissions, sharing consumption data, communicating information about sustainable actions taken, financial movements or sharing problems and barriers encountered in the process of developing sustainable habits.

PR2: ADOPTION OF NEW VALUES FOR NEW BUSINESS MODELS

(Poponi et al. 2019; Siriporananon and Visuthismajarn 2018)

(Poponi et al.

PR3:

DEVELOPMENT

OF NEW

TECHNOLOGIES

FOR NEW

BUSINESS

MODELS

2019)
This policy is related to the adoption of new business values such as the adoption of an inclusive and sustainable economy, low carbon emission practices or sustainable habits like recycling, in order to pursue sustainable production and resource consumption.

This policy consists of developing technologies to transform private companies into new business models that seek profit while also generating social benefit, such as social vulnerability reduction. For example, investing in sustainable technology makes companies reduce their emissions, which reduces pollution and increases social welfare.
COMMUNITY GROUPS
CG1: ORGANIZE EVENTS AND WORKSHOPS
(Poponi et al. 2019)
This policy consists of organizing events and workshops to discuss the main concerns and problems derived from $\mathrm{CC}$ such as decreased societal welfare due to the effects of CC, vulnerabilities due to new climate scenarios or the lack of knowledge concerning what to do or how to act in a sustainable way. 


\begin{tabular}{|lll|}
\hline POLICY & REFERENCE & DEFINITION \\
\hline $\begin{array}{l}\text { CG2: ORGANIZE } \\
\text { CAMPAIGNS }\end{array}$ & $\begin{array}{l}\text { (Poponi et al. } \\
\text { 2019) }\end{array}$ & $\begin{array}{l}\text { This policy consists of organizing } \\
\text { campaigns through social networks, media } \\
\text { or physical events with the objective of } \\
\text { creating a positive impact on the awareness } \\
\text { of the three stakeholder types, but with } \\
\text { greater emphasis on community groups. }\end{array}$ \\
\hline CG3: DEMAND A & $\begin{array}{l}\text { (Bakaki and } \\
\text { Bernauer, } \\
2017)\end{array}$ & $\begin{array}{l}\text { This policy consists of demanding that } \\
\text { public entities and private companies change } \\
\text { the way they face the challenge of CC. To } \\
\text { that end, demanding action and } \\
\text { transparency concerning their decisions and } \\
\text { emissions is posed in this policy in order to } \\
\text { ensure good sustainable practices are } \\
\text { adopted and enabled. }\end{array}$ \\
\hline
\end{tabular}

\section{Case Studies}

Two case studies were conducted to confirm that the framework fulfilled its aim of providing guidance and support to cities when developing climate awareness. During both case studies, a set of semistructured interviews were conducted.

Participants were asked to evaluate the implementation level of the policies based on their expertise and experience on a scale of from 0 to $100 \%$. For each implementation percentage given, participants provided the pieces of evidence and barriers that justify their assessment. Figure 4 (left) shows the average effort allocated to implement each policy in the case of Kristiansand, and Fig. 4 (right) shows the same for Donostia.

In the case study of Kristiansand, the answers given in the semi-structured interviews indicated that Kristiansand was in the second step-and nearly in the third step-of the awareness-development process. Concretely, the main conclusion from the Kristiansand case was that even though public entities have made efforts to build a climate-resilient city and transform Kristiansand into a sustainable city, the efforts made will not be effective if private entities are not engaged in adopting new habits and community groups do not participate. The interviews concluded that public entities in Kristiansand are the most aware stakeholders and they seek to increase both private companies and community groups awareness. Community groups also understand and perceive $\mathrm{CC}$, but their active participation has not yet been achieved. Finally, private companies are the least aware stakeholder, which makes sense given the industrial history and the dominant type of sector (oil and gas industry), which is used to business-asusual habits. However, consultancies that are trying to boost climate awareness development have emerged.

As for the responses gathered in Donostia, this city was determined to be at the beginning of the second step of the awareness-development process. The main highlights were that there was a big difference among the awareness level of the stakeholders, some being in the early steps and others willing to be in 
the third and even in the fourth step. The main conclusion from the case study of Donostia was that public entities are the most aware stakeholders, followed by private companies and then community groups. However, the barriers that the city is addressing, such as lack of commitment from public entities due to being in a situation of comfort, are hampering the process. Private companies also show quite high awareness levels since the answers given were from participants that represented companies that are already climate aware. However, the reality described by the experts in Donostia is similar to Kristiansand's, namely that the industrial history of the city keeps the companies tied to their business-asusual habits. Lastly, community groups happen to be the stakeholders with the lowest climate awareness level, but they have also demonstrated that they perceive and are committed to dealing with CC. Yet as they are mostly emerging groups, their main barrier is that they are newcomers to the issue. Hence, as time passes, the implementation level of community groups in Donostia will increase and so will their climate awareness level. In summary, Donostia perceives and understands that CC is a hazard, yet it still needs to develop committed participation and collaboration to become fully climate aware.

Table 4 compares both cities based on the results obtained. Note that the proposed framework suggests an effective implementation order of the policies, specifying when a policy should be fully implemented and what steps should be maintained over time. This means that, even if participants state that an effort of $80 \%$ has been made in implementing a policy, if the preceding policy has not been at least partially implemented, the effectivity of the implementation decreases. Bearing this in mind, Table 4 summarizes the effective implementation level of the policies taking into account the evidence and barriers gathered in both case studies and the climate awareness development process defined in the framework.

On the one hand, as a consequence of lived experiences, Kristiansand has made an effort to implement policies such as PU1 and PU2, in which public entities seek to boost private companies' climate awareness. In this sense, a positive impact can be noted in private companies that have started to implement policies like PR1 and PR2, having been incentivized by public entities. However, the low effort made on policies like PR3 or the low participation of community groups in policies like CG3 hampers effective implementation of the policies and in turn Kristiansand's climate development. Somehow, the lack of sensitization action led by public entities along with the passivity and stigma of community groups to participate in mobilizations keep climate awareness from developing in a timely and efficient manner. That is why the values in Table 4 are lower than the values in Fig. 4 for policies like PR1, PR2, CG1 and CG2. In sum, even though the efforts of public entities have started to have an effect in terms of developing climate awareness, the lack of participation is hampering the effective increase in awareness.

On the other hand, Donostia is starting to implement the key policies to develop climate awareness under the leadership of public entities. However, the lack of pressure from community groups through policies such as CG3, have made public entities become conformist with the policies they have implemented, and proactivity is not encouraged. In this sense, Donostia needs time, since the community groups that will actually demand change are emerging and will seek to boost both public and private entities' climate awareness. For instance, private companies have already started to allocate some effort to developing awareness, mostly in new companies. But companies do not feel pressure to put an end up to their 
business-as-usual mentality, shift into climate awareness, and become sustainable companies. That is why in Table 4 policies like PU2, PU3 or CG1 have lower implementation values than the efforts represented in Fig. 4.

Both cities are coastal and both cities have experienced CC impacts and consequently started to develop climate awareness both locally and through international networks. Yet the case studies show that Kristiansand has a higher climate awareness level than Donostia does. The main difference that is keeping Donostia behind Kristiansand is the existence of barriers such as the lack of non-conformity that is hampering the proper implementation of policies by public entities. This directly affects private companies' climate awareness development. In this sense, Kristiansand has allocated greater effort in developing climate awareness in recent years. The results show how Kristiansand is more advanced in those policies that it has focused on, whereas Donostia presents a more homogenized level of policy implementation.

\section{Discussion And Conclusions}

The framework presented in this paper takes a step forward and proposes an ideal process for developing city stakeholder climate awareness. The co-creation process used in this study has ensured that the theory found in the literature as well as the expertise and practice of city stakeholders and case studies are considered. In this sense, the framework is developed as a theoretical tool that addresses the awareness-development process at a strategic-aggregated level. One of the main conclusions from the co-creation process is that for awareness to start developing, cities first need to have a CC-related experience. As a result of the lived experiences, cities will realise the cost of inaction and start to develop knowledge about how to face $\mathrm{CC}$ and attention concerning $\mathrm{CC}$ events. Having attention and knowledge will get city stakeholders to behave proactively in a committed way and they will start to create a collaboration network that will maintain the climate awareness levels over time. Hence, four attributesexperience, attention, knowledge and collaboration-are developed in the awareness-development process.

The initial hypothesis of our research was that developing city stakeholders' awareness of CC would increase the effectiveness of climate-resilience operationalization. The co-creation process carried out corroborates that developing city stakeholders' awareness increases stakeholders' experience, knowledge, attention and collaboration (Sect. 4.2). Consequently, increasing awareness and boosting the effective implementation of the city's CC-resilience-building plans. It is important to bear in mind that awareness is not the only factor affecting the effectiveness of the operationalization of the resilience-building plans. As addressed at the beginning of the paper, operationalizing resilience is also dependent on cities' social systems, economic system, natural resources and infrastructure.

Moreover, the framework includes the policies that each type of city stakeholder should lead. The policies show how community groups are the ones who demand a change, public entities lead the awarenessdevelopment process, and private companies are the last city stakeholder type to become engaged in the 
process, because they see $\mathrm{CC}$ as an opportunity to grow rather than a risk. As concluded in the case studies in Kristiansand and Donostia, the framework enables a city to assess its climate awarenessdevelopment by assessing the policy implementation levels. During the case studies, the participating stakeholders noted the policies have been defined at an aggregated level. Hence, they suggested that for future research concrete actions be added to complement the policies and facilitate the understanding of the climate awareness-development process.

Finally, the case studies have shown that the framework accomplish its aim of contributing to the lack of climate awareness development processes. The case studies gave both cities the opportunity to assess their current climate awareness level, determine their next steps in improving their climate awareness and understand the overall process needed to take those steps. In this vein, the experts attested to the importance of having had the explicit explanation of the process for boosting and facilitating the proper development of climate awareness and decreasing the duplication and waste of effort. Therefore, we concluded from the experts' point of view that the Climate Awareness Development framework is of great utility when it comes to understanding the climate awareness development process and learning about the steps for moving forward.

\section{Declarations}

\section{ACKNOWLEDGEMENTS}

The authors gratefully acknowledge the financial support provided by the Basque Government through the Predoctoral Researcher Training Scholarship Programme for the 2019-2020 academic year. This research was funded by LIFE IP URBAN KLIMA 2050, grant number LIFE18 IPC/ES/000001.

\section{Ethics approval:}

Not applicable' for that section. This study is exempted from ethical approval by ethics committee.

\section{Consent to participate}

All authors agreed on participating in the published version of the manuscript.

\section{Consent to publish}

All authors have read and agreed to publish this version of the manuscript.

\section{Author Contributions:}

All authors contributed to the paper. The introduction, state of the art, discussion and conclusion - M.I. Research methodology and Development of the framework - J.H., L.L. and M.I. Case Studies - L.L. and M.I.. Writing, review and editing - M.I., J.I., L.L.

\section{Funding:}


This research was funded by LIFE IP URBAN KLIMA 2050, grant number LIFE18 IPC/ES/000001 and a pre-doctoral grant from the Basque Country.

\section{Competing interests}

The authors declare that they have no competing interests.

\section{Availability of data and materials}

Data sharing not applicable to this article as no datasets were generated or analysed during the current study.

\section{References}

1. Al-Awadhi, T., Charabi, Y., \& Choudri, B. S. (2019). Pathways for building urban resilience to climate change in Oman. Development in Practice, 29(5), 594-605.

2. Arnstein, S. R. (1969). A Ladder Of Citizen Participation. Journal of the American Planning Association, 35(4):216-224. https://doi.org/10.1080/01944366908977225

3. Anguelovski I., Chu E., and Carmin J.O. (2014). Variations in Approaches to Urban Climate Adaptation: Experiences and Experimentation from the Global South. Global Environmental Change 27(1): 156-67. http://dx.doi.org/10.1016/j.gloenvcha.2014.05.010.

4. Bakaki, Z., and Bernauer, T. (2017). Do global climate summits influence public awareness and policy preferences concerning CC? Environmental Politics, 26(1):1-26.

https://doi.org/10.1080/09644016.2016.1244964

5. Berndtsson, R.; Becker, P.; Persson, A.; Aspegren, H.; Haghighatafshar, S.; Jönsson, K.; ... Tussupova, K. (2019). Drivers of changing urban flood risk: A framework for action. J. Environ. Manag. 240, 47-56. https://doi.org/10.1016/J.JENVMAN.2019.03.094

6. Burnside-Lawry, J., and Carvalho, L. (2016). A stakeholder approach to building community resilience: awareness to implementation. International Journal of Disaster Resilience in the Built Environment, 7(1):4-25. https://doi.org/10.1108/IJDRBE-07-2013-0028

7. Dalkey, N. (1969). An experimental study of group opinion: The Delphi method. Futures, 1(5):408426. https://doi.org/https://doi.org/10.1016/S0016-3287(69)80025-X

8. Drummond, A., Hall, L. C., Sauer, J. D., and Palmer, M. A. (2018). Is public awareness and perceived threat of climate change associated with governmental mitigation targets?. Climatic change, 149(2):159-171.

9. Evers, M., Jonoski, A., Almoradie, A., and Lange, L. (2016). Collaborative decision making in sustainable flood risk management: A socio-technical approach and tools for participatory governance. Environmental Science \& Policy, 55, 335-344.

10. Gifford, R., Kormos, C., and McIntyre, A. (2011). Behavioral dimensions of CC: Drivers, responses, barriers, and interventions. Wiley Interdisciplinary Reviews: Climate Change, 2(6):801-827. 
https://doi.org/10.1002/wcc.143

11. Gimenez, R., Labaka, L., and Hernantes, J. (2017). A Maturity Model for the Involvement of Stakeholders in the City Resilience Building Process. Technological Forecasting and Social Change, 121:7-16. https://doi.org/10.1016/j.techfore.2016.08.001

12. González-Hernández, D.L., Meijles, E.W., Vanclay, F., (2019). Factors that Influence Climate Change Mitigation and Adaptation Action: A Household Study in the Nuevo Leon Region, Mexico. Climate 7, 74. https://doi.org/10.3390/cli7060074

13. Guo, B., Geng, Y., Sterr, T., Zhu, Q., and Liu, Y. (2017). Investigating public awareness on circular economy in western China: A case of Urumqi Midong. Journal of Cleaner Production, 142: 21772186. https://doi.org/10.1016/j.jclepro.2016.11.063

14. Hamilton L.C., and Stampone M.D. (2013). Blowin' in the wind: short-term weather and belief in anthropogenic climate change. Weather, Climate, and Society 5(2):112-119. doi:10.1175/WCAS-D12-00048.1

15. Henly-Shepard, S., Gray, S. A., and Cox, L. J. (2015). The use of participatory modeling to promote social learning and facilitate community disaster planning. Environmental Science and Policy, 45, 109-122. https://doi.org/10.1016/j.envsci.2014.10.004

16. IPCC. (2018). An IPCC Special Report on the impacts of global warming of $1.5^{\circ} \mathrm{C}$ above pre-industrial levels and related global greenhouse gas emission pathways, in the context of strengthening the global response to the threat of CC. https://doi.org/10.1017/CB09781107415324

17. Iturriza, M., Labaka, L., Ormazabal, M., and Borges, M. (2020). Awareness-development in the context of climate change resilience. Urban Climate, 32, 100613.

18. Jick T.D. (1979) Mixing Qualitative and Quantitative Methods: Triangulation in Action Mixing Qualitative and Quantitative Methods: Triangulation in Action. Administrative Science Quarterly.

19. Keenan, J. M. (2018). Types and forms of resilience in local planning in the U. S.: Who does what? Environmental Science and Policy, 88:116-123. https://doi.org/10.1016/j.envsci.2018.06.015

20. Larson, L. R.; Lauber, T. B.; Kay, D. L.; Cutts, B. B. (2017). Local Government Capacity to Respond to Environmental Change: Insights from Towns in New York State. J. Environ. Manag. 60(1), 118-135. https://doi.org/10.1007/s00267-017-0860-1

21. Lieske, D. J., Wade, T., and Ann, L. (2014). Estuarine, Coastal and Shelf Science Climate change awareness and strategies for communicating the risk of coastal flooding: A Canadian Maritime case example. Estuarine, Coastal and Shelf Science, 140:83-94.

https://doi.org/10.1016/j.ecss.2013.04.017

22. Liu, X.; Liu, B.; Shishime, T.; Yu, Q.; Bi, J.; Fujitsuka, T. (2010). An empirical study on the driving mechanism of proactive corporate environmental management in China. J. Environ. Manag. 91(8), 1707-1717. https://doi.org/10.1016/j.jenvman.2010.03.011

23. Luís, S., Vauclair, C.M., and Lima, M.L. (2018). Raising Awareness of CC Causes? Cross-National Evidence for the Normalization of Societal Risk Perception of CC. Environmental Science and Policy 80: 74-81. https://doi.org/10.1016/j.envsci.2017.11.015. 
24. Moglia, M., Cork, S. J., Boschetti, F., Cook, S., and Bohensky, E. (2018). Urban transformation stories for the 21st century: Insights from strategic conversations Urban transformation stories for the 21st century: Insights from strategic conversations. Global Environmental Change, 50:222-237. https://doi.org/10.1016/j.gloenvcha.2018.04.009

25. Morgan, D. (1997). Focus Groups as Qualitative Research, 16. https://doi.org/10.4135/9781412984287

26. Moser, S.C. (2016). Reflections on CC communication research and practice in the second decade of the 21 st century: What more is there to say? Wiley Interdisciplinary Reviews: Climate Change, 7(3):345-369. https://doi.org/10.1002/wcc.403

27. Neo, S. M.; Choong, W. W.; Ahamad, R. Bin. (2017). Differential environmental psychological factors in determining low carbon behaviour among urban and suburban residents through responsible environmental behaviour model. Sustain. Cities Soc., 31, 225-233. https://doi.org/10.1016/j.scs.2017.03.003

28. Nguyen, K.A.T.; Jolly, C. M.; Le, T.; Bui, C. (2015). Climate change awareness, coping mechanisms and adaptation in poor rural coastal communities, Ben Tre Province, Vietnam. Inter. J. Glob. Warm. 8(3), 416-435. https://doi.org/10.1504/IJGW.2015.072658

29. Olazabal, M., Galarraga, I., Ford, J., Sainz De Murieta, E., and Lesnikowski, A. (2019). Are local climate adaptation policies credible? A conceptual and operational assessment framework. International Journal of Urban Sustainable Development, 3138. https://doi.org/10.1080/19463138.2019.1583234

30. Oxley, M. C. (2013). A "People-centred Principles-based" post-Hyogo framework to strengthen the resilience of nations and communities. International Journal of Disaster Risk Reduction, (4), 1-9.

31. Paterson, B., and Charles, A. (2019). Community-based responses to climate hazards: typology and global analysis. Climatic Change, 152(3), 327-343.

32. Pescaroli, G. (2018). Perceptions of cascading risk and interconnected failures in emergency planning: Implications for operational resilience and policy making. International Journal of Disaster Risk Reduction. 1-12. https://doi.org/10.1016/j.ijdrr.2018.01.019

33. Poponi, S., Colantoni, A., Cividino, S. R. S., and Mosconi, E. M. (2019). The Stakeholders ' Perspective within the B Corp Certification for a Circular Approach, 1-15. https://doi.org/10.3390/su11061584

34. Prescott, S. L.; Hancock, T.; Bland, J.; van den Bosch, M. van den, Jansson, J. K.; Johnson, C. C.; ... Wegienka, G. (2019). Eighth Annual Conference of inVIVO Planetary Health: From Challenges to Opportunities. Inter J Enviro. Re. Pub. Health. 16(21), 4302. https://doi.org/10.3390/ijerph16214302

35. Rogers, R. W. (1975). A Protection Motivation Theory of Fear Appeals and Attitude Change1. The Journal of Psychology. 91(1):93-114. https://doi.org/10.1080/00223980.1975.9915803

36. Saxena, A., Qui, K. and Robinson. (2018). Knowledge, attitudes and practices of climate adaptation actors towards resilience and transformation in a $1.5^{\circ} \mathrm{C}$ world. Environ. Sci. Policy. 80:152-159. doi:10.1016/j.envsci.2017.11.001.

37. Sheppard, S.R.J., Shaw, A., Flanders, D., Burch, S., Wiek, A., Carmichael, J., Cohen, S. (2011). Future visioning of local CC: A framework for community engagement and planning with scenarios and 
visualisation. Futures. 43(4):400-412. https://doi.org/10.1016/j.futures.2011.01.009

38. Shrouf, F., Gong, B., and Ordieres-Meré, J. (2017). Multi-level awareness of energy used in production processes. Journal of cleaner production, 142:2570-2585.

39. Simonet, G., and Leseur, A. (2019). “Barriers and drivers to adaptation to climate change-a field study of ten French local authorities. Climatic Change, 155(4), 621-637.

40. Siriporananon, S., Visuthismajarn, P., (2018). Kasetsart Journal of Social Sciences Key success factors of disaster management policy: A case study of the Asian cities climate change resilience network in Hat Yai city, Thailand. Kasetsart J. Soc. Sci. 39,269-276. https://doi.org/10.1016/j.kjss.2018.01.005

41. Sollberger S., Bernauer T., and Ehlert U. (2017). Predictors of visual attention to climate change images: An eye-tracking study. Journal of Environmental Psychology, 51:46-56. Available at: http://dx.doi.org/10.1016/j.jenvp.2017.03.001.

42. Street, R., Di Mauro, M., Humphrey, K., Johns, D., Boyd, E., Crawford-Brown, D., Evans, J., Kitchen, J., Hunt, A., Knox, K., Low, R., McCall, R., Watkiss, P., \& Wilby, R. (2016). UK Climate Change Risk Assessment Evidence Report: Chapter 8, Cross-cutting Issues. Report prepared for the Adaptation Sub-Committee of the Committee on Climate Change, London.

43. Tàbara, J. D., Dai, X., Jia, G., McEvoy, D., Neufeldt, H., Serra, A., ... West, J. J. (2010). The climate learning ladder. A pragmatic procedure to support climate adaptation. Environmental Policy and Governance, 20(1),1-11. https://doi.org/10.1002/eet.530

44. Torabi, E., Dedekorkut-Howes, A., and Howes, M. (2018). Adapting or maladapting: Building resilience to climate-related disasters in coastal cities. Cities, 72:295-309.

https://doi.org/10.1016/j.cities.2017.09.008

45. Toubin, M., Laganier, R., Diab, Y., and Serre, D. (2014). Improving the conditions for urban resilience through collaborative learning of Parisian urban services. Journal of urban planning and development,141(4), 05014021.

46. UNISDR. (2009). Terminology on Disaster Risk Reduction. International Strategy for Disaster Reduction (ISDR). 1-30. Retrieved from www.unisdr.org/publications

47. Xie, B., Brewer, M. B., Hayes, B. K., McDonald, R. I., and Newell, B. R. (2019). Predicting CC risk perception and willingness to act. Journal of Environmental Psychology, 65, 101331. https://doi.org/10.1016/j.jenvp.2019.101331

48. Yin, B. C. L.; Laing, R.; Leon, M.; Mabon, L. An evaluation of sustainable construction perceptions and practices in Singapore. Sustain. Cities Soc. (2018), 39, 613-620. https://doi.org/10.1016/J.SCS.2018.03.024

\section{Tables}

Due to technical limitations, table 2,4 is only available as a download in the Supplemental Files section. 


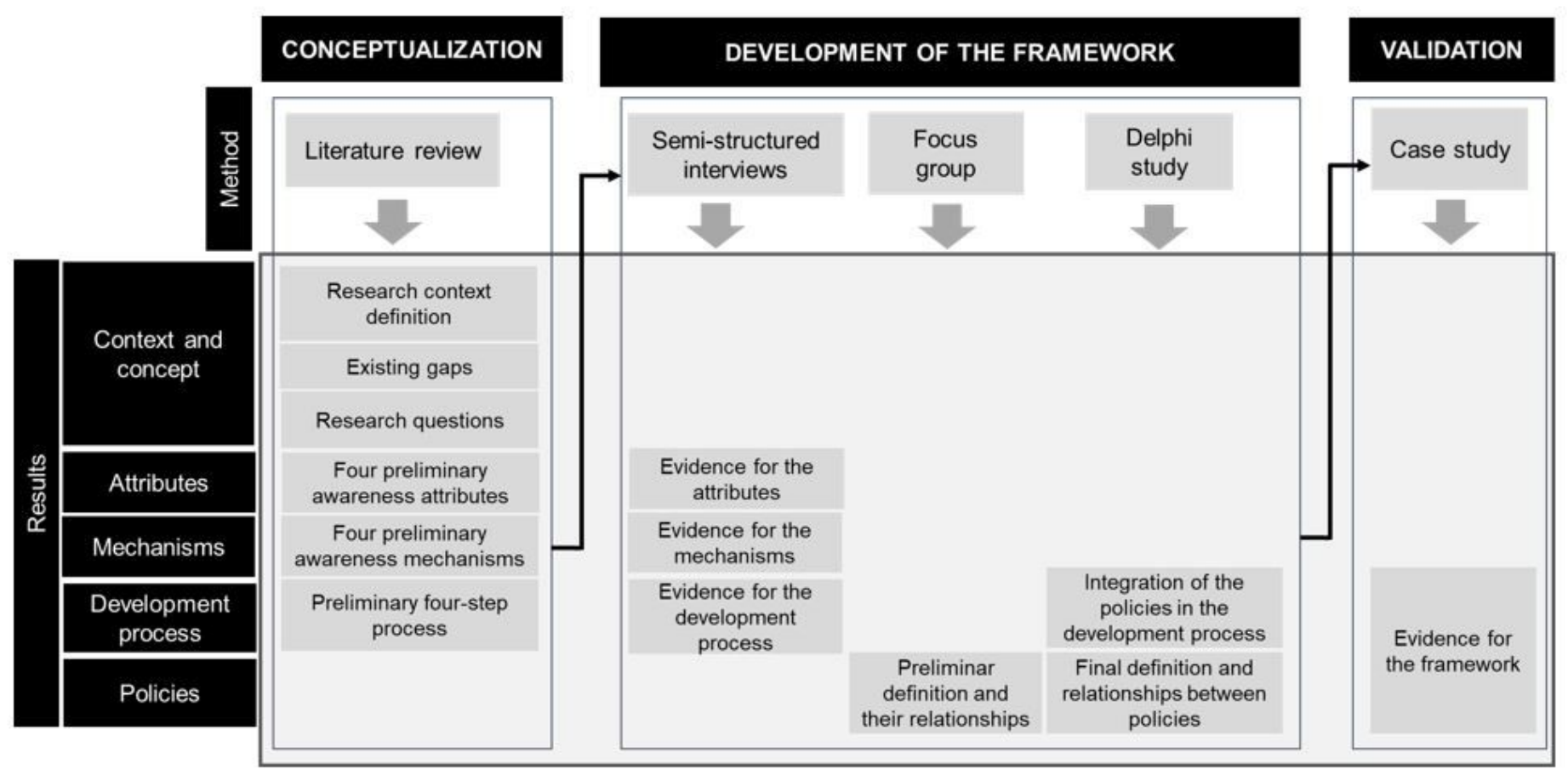

Figure 1

Research methodology 


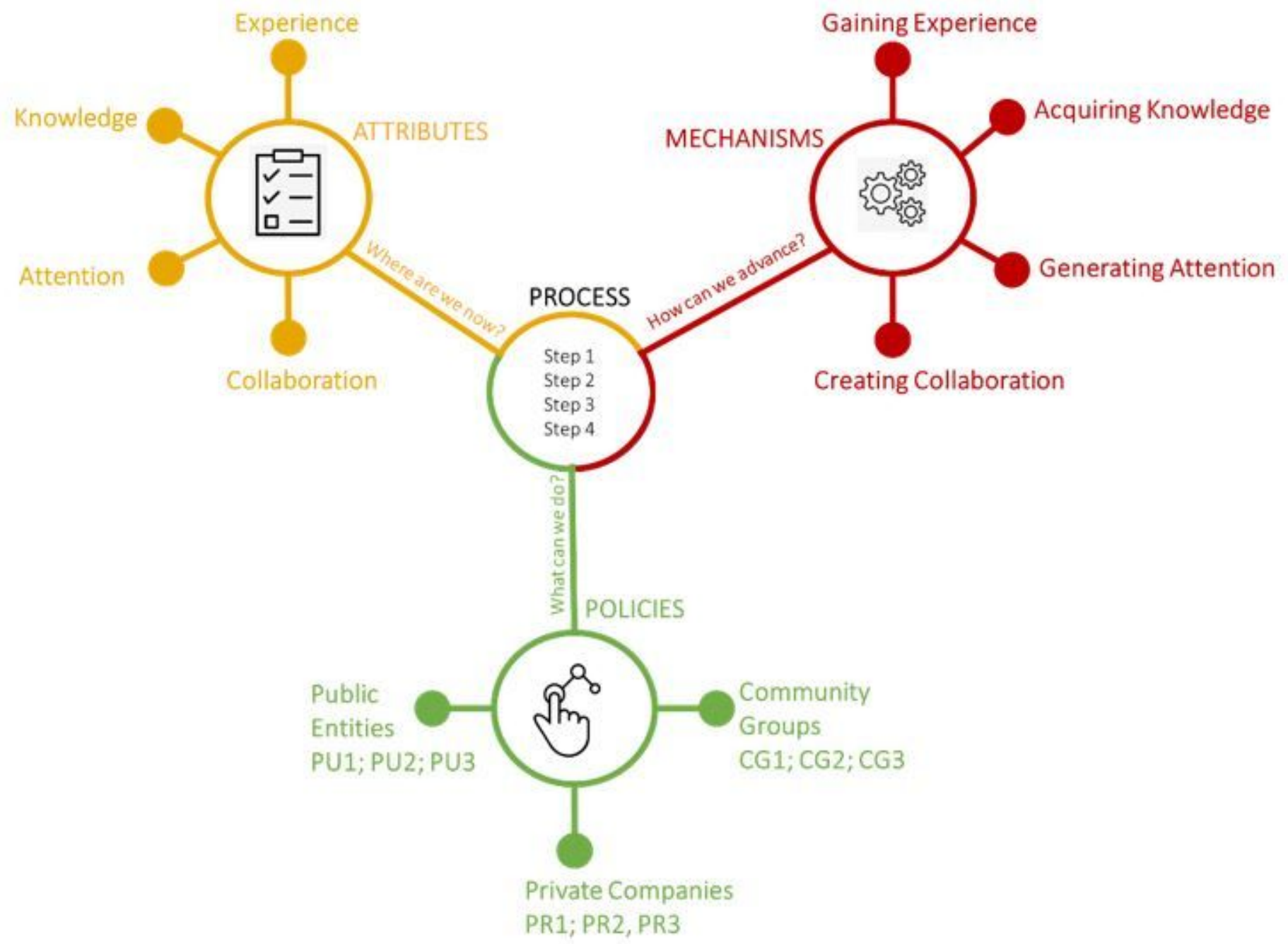

Figure 2

Elements composing the framework

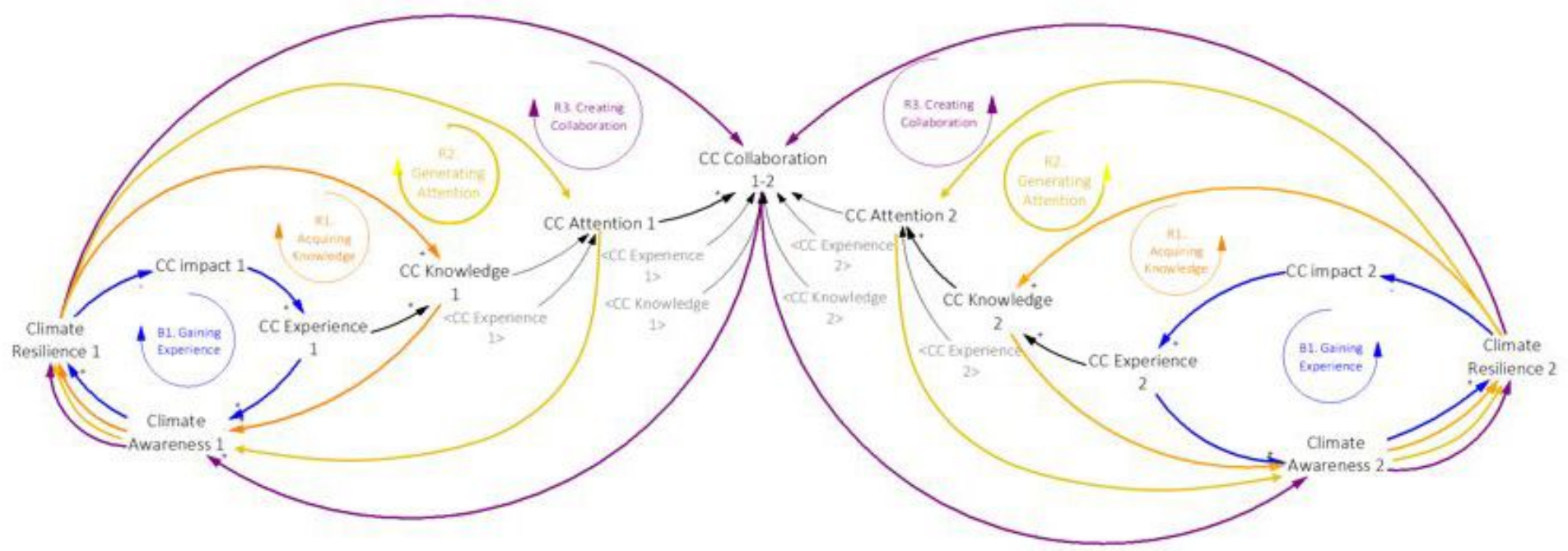




\section{Figure 3}

Causal loop diagram of the framework showing the relationships among the mechanisms and attributes
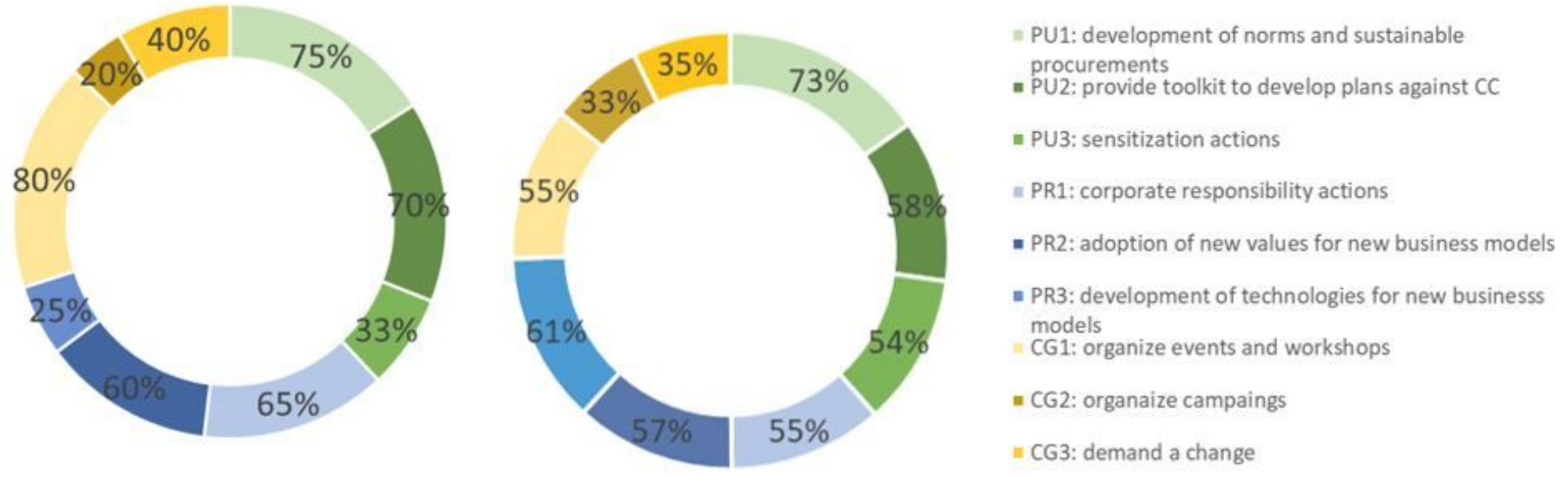

Figure 4

Efforts made in implementing the policies in Kristianstad (left) and Donostia (right)

\section{Supplementary Files}

This is a list of supplementary files associated with this preprint. Click to download.

- Table2.jpg

- Table4.jpg 